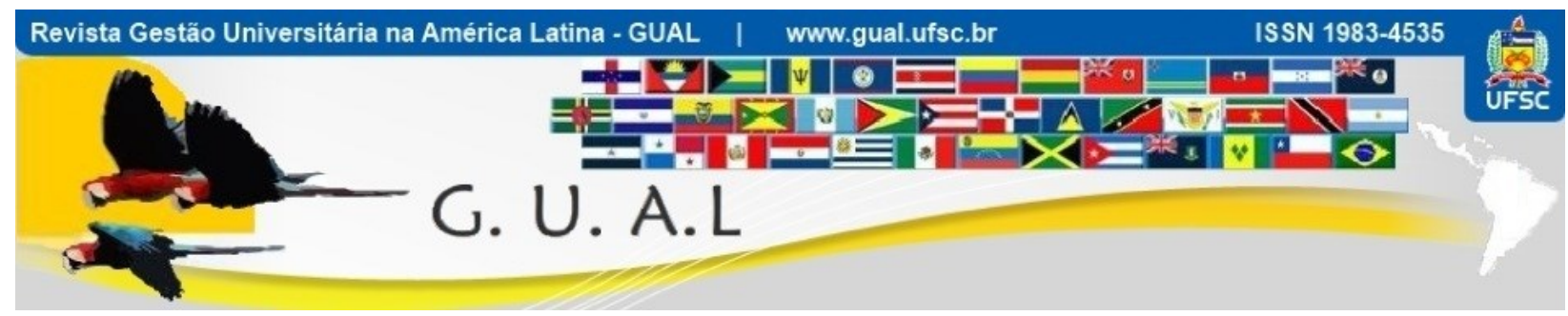

DOI: http://dx.doi.org/10.5007/1983-4535.2016v9n2p113

\title{
COMPETÊNCIAS DOCENTES SOB A ÓTICA DE PROFISSIONAIS NA TRANSIÇÃO DE CARREIRA DO MUNDO CORPORATIVO PARA O ACADÊMICO: UM ESTUDO DE CORTE LONGITUDINAL
}

\section{TEACHING COMPETENCES ACCORDING TO PROFESSIONALS WHO MADE A TRANSITION FROM THE CORPORATE WORLD TO THE ACADEMIA: A LONGITUDINAL STUDY}

Silvino Paulino dos Santos Neto, Mestre Universidade Fundação Mineira de Educação e Cultura - FUMEC silvinosantos.acad@gmail.com

Zélia Miranda Kilimnik, Doutora Universidade Fundação Mineira de Educação e Cultura - FUMEC zeliamk@gmail.com

Anderson de Souza Sant'Anna, Pós-Doutor Fundação Dom Cabral anderson@fdc.org.br

Recebido em 03/julho/2014

Aprovado em 16/novembro/2015

Sistema de Avaliação: Double Blind Review

Esta obra está sob uma Licença Creative Commons Atribuição-Uso. 


\title{
RESUMO
}

Este artigo visa dar continuidade a estudo realizado por Kilimnik et al. (2011) - assim como em estudos prévios conduzidos sobre o tema por Kilimnik, Correa e Oliveira (2009a) e Kilimnik e Correa (2009b) - sobre competências de profissionais e gestores que procederam a transições de carreira do mundo corporativo para o acadêmico. Retomando a proposta original desses autores, busca-se, após cinco anos, investigar eventuais alterações em suas competências docentes, bem como identificar estratégias didático-pedagógicas utilizadas. Recorrendo à abordagem qualitativa - a presente pesquisa envolveu a realização de 25 entrevistas semiestruturadas e em profundidade, em uma perspectiva longitudinal. Foi procedida a análise de conteúdo das entrevistas, com o auxílio do software QDA Miner. Os resultados corroboraram parte significativa das competências identificadas na pesquisa anterior, tais como conhecimento específico na área, relacionamento interpessoal e experiência de mercado. Detectou-se também que os pesquisados buscam transferir as experiências do mundo corporativo para o mundo acadêmico, ao utilizar técnicas de ensino como estudo de casos e dinâmicas. Segundo os próprios pesquisados, experiência profissional, apesar de ser um dos pontos fortes do docente oriundo do mundo corporativo, não se constitui suficiente, caso não se associe com a teoria, gerando aprendizado.

Palavras Chave: Competências. Transição de carreira. Carreira acadêmica.

\begin{abstract}
This article aims to continue the study by Kilimnik et al. (2011) - as in previous studies conducted on the subject by Kilimnik, Correa Oliveira (2009a) and Kilimnik and Correa (2009b) - on professional skills and managers who made a career transition from corporations to the academic field. Using these authors' original proposal five years after their research, we seek to investigate any changes in their teaching skills as well as to identify didactic and pedagogical strategies used. Adopting the qualitative approach as done previously, this research features a longitudinal cohort study and it involved conducting 25 semi-structured interviews in depth with individuals who participated in the previous empirical survey. The content analysis of interviews was carried out with the help of the QDA Miner software. The results confirm a significant part of the competencies identified in the previous survey. It was also verified that the respondents seek to transfer the experience of the corporate world to the academia using educational techniques such as case studies and dynamics. According to the respondents themselves, work experience, despite being one of the strengths they brought from the corporate world, is not enough if not associated with theory, generating learning.
\end{abstract}

Key Words: Skills. Career transition. Academic career. 


\section{INTRODUÇÃO}

Especialmente neste século, percebe-se as organizações continuamente revisitando suas estratégias, procurando redefinir seus mercados e estruturas. Mudanças sempre se deram no contexto organizacional. No entanto, elas se distinguem, contemporaneamente, pelo ritmo em que se processam. Sem dúvida, as organizações vivenciam redução sem precedentes nos ciclos de vida de seus modelos de negócios, processos e dinâmicas produtivas, com efeitos indeléveis sobre gestão de pessoas e, particularmente, sobre suas careiras e trajetórias profissionais (BARUCH, 2011). Em decorrência, registra-se número crescente de profissionais e gestores do mundo corporativo direcionando-se para carreiras "alternativas" ou paralelas - em outros segmentos, em especial, o acadêmico. Isto, como forma de profilaxia à perda de posições atuais, bem como para viabilizar novas oportunidades de reinserção no mercado de trabalho.

Segundo Simendinger et al. (2011), uma alternativa para aumentar as chances de sucesso de perfis mais executivos que chegam às universidades consiste em identificar, aprimorar e complementarizar suas competências instaladas àquelas específicas ao exercício da docência. O resultado seria um corpo docente qualificado que conjugaria competências relacionadas às práticas organizacionais, com estratégicas didático pedagógicas aderentes às demandas relativas à transferência de conhecimentos.

Nesse contexto, a noção de competência pode ser compreendida como a "[...] capacidade de a pessoa assumir iniciativas, ir além das atividades prescritas, ser capaz de compreender e dominar novas situações no trabalho, ser responsável e ser reconhecido por isso" (ZARIFIAN, 2001, p.111).

Tendo por base tal problemática, a presente pesquisa visa dar continuidade a estudo realizado Kilimnik et al. (2011) - assim como a estudos prévios conduzidos sobre o tema por Kilimnik, Correa e Oliveira (2009a) e Kilimnik e Correa (2009b) - em que foram investigados os principais atributos de competência a para uma bem-sucedida transição de carreira do mundo corporativo para o acadêmico. Na oportunidade, os pesquisadores realizaram 50 entrevistas com profissionais que vivenciavam tal transição. Por meio de análise de conteúdo, eles detectaram competências agrupadas em seis categorias: didática, planejamento, comunicação, argumentação, autoconfiança e disciplina.

Partindo desses achados, propõe-se, sob um corte longitudinal, compartilhar resultados de estudo mais recente em que se intentou identificar percepções de integrantes desse mesmo 
grupo de pesquisados quanto às competências docentes, bem como estratégias didáticopedagógicas adotadas, passados cinco anos do estudo original.

\section{FUNDAMENTAÇÃO TEÓRICA}

Nesse tópico serão revisitados os construtos centrais da pesquisa, os quais serviram de referência para o estudo que subsidiou os resultados deste artigo.

\subsection{A NOÇÃO DE TRANSIÇÃO DE CARREIRA}

Para Riverin-Simard (1993), no atual estágio do processo de produção e regulação capitalista, a transição de carreira afeta extensa gama de profissionais e gestores, configurando processo dinâmico, que repercute muito além da esfera profissional. Sob esse enfoque, a autora define a transição de carreira como um processo de deslocamento para uma diferente etapa do desenvolvimento profissional, tornando-se igualmente uma transição socioprofissional.

Número significativo de transições, no entanto, não decorrem de planejamentos prévios. Ao contrário são involuntárias, provocadas por eventos da vida, como um divórcio, uma mudança de cidade ou, mais comumente, pela perda do emprego. A própria pessoa, no entanto, pode se colocar, no decorrer de sua vida, em permanente posição de transição, por exemplo, adquirindo conhecimentos em outras áreas e ou especializações (RIVERINSIMARD, 1993).

Já para Duberley (2011), a transição de carreira é definida como o período em que um indivíduo troca objetivamente de papéis, muda sua orientação profissional ou foco de função, caracterizando, desse modo, uma transição que envolve, além de elementos objetivos, um estrito caráter subjetivo.

Veloso (2012), por sua vez, salienta ser necessário explorar o fato de que transições impõem transposição de certas fronteiras. A autora refere-se a Gunz e Peiperl (2007), para ressaltar que, em primeiro lugar, as carreiras são compostas pelo movimento através de uma paisagem formada por networks complexas da sociedade econômica. As fronteiras das carreiras são, desse modo, as linhas nas quais a paisagem social, marcada por descontinuidades, pontua quais os obstáculos desses movimentos. Algumas dessas fronteiras criam interrupções menores; outras, maiores, permitindo somente a algumas pessoas ultrapassá-las. Em segundo lugar, as fronteiras de carreira são socialmente construídas. 
Dividem-se em fronteiras subjetivas e objetivas. As fronteiras subjetivas são propriedade dos indivíduos, são construídas na mente das pessoas que as experimentam. Assim, o indivíduo alimenta crenças sobre uma determinada transição, por exemplo, quanto ao maior ou menor grau de risco envolvido, assim como quanto ao seu preparo para tal. Já as fronteiras objetivas são propriedades das entidades sociais, como organizações, ocupações ou comunidade. São comumente alimentadas por crenças sobre determinada classe de transições de funções, emergem de um consenso dos atores de carreira, no qual são criados protótipos de fronteiras, que definem os estágios de carreira (VELOSO, 2012).

Veloso (2012), corroborando Duberley (2011), conclui ser possível que a transição profissional envolva movimentos entre organizações, funções e profissões - que seriam as fronteiras objetivas - e entre crenças e padrões atitudinais pessoais - denominadas fronteiras subjetivas.

De acordo com Duberley, Cohen e Mallon (2007), ainda que por décadas tenha havido demanda por uma teoria sobre transição ocupacional que levasse em conta, tanto causalidades contextuais quanto individuais, as primeiras raramente foram contempladas. Para essas autoras, a necessidade de pesquisas que possam analisar as transições dos indivíduos dentro de diferentes grupos profissionais, vivenciando mudanças institucionais de grande escala, fazem-se oportunas. Ademais, argumentam que esquemas para compreensão das transições de carreira devem transcender análises simplistas e dualistas, incorporando relações recursivas entre mudanças institucionais e individuais.

\subsection{A NOÇÃO DE COMPETÊNCIA}

A transição do mundo corporativo para o acadêmico não implica apenas o movimento de um espaço ocupacional para outro ou a interrupção de um processo dentro de uma carreira para o início de outro em outra carreira. Ao contrário, envolve o desenvolvimento de competências, isto na medida em que as compreendemos como um conceito dinâmico, que se atualiza permanentemente, variando de acordo com o profissional, a organização e o macrocontexto em que se situam (LE BOTERF, 2003).

De modo geral, pode-se identificar na literatura especializada múltiplas definições acerca da noção de competência. A inexistência de consenso, além de divergências de caráter filosófico e ideológico podem, também, ser atribuídas à adoção da expressão com diferentes enfoques, em diferentes áreas do conhecimento (KILIMNIK e SANT’ANNA, 2006). Dutra 
(2004), no entanto, identifica a existência de duas abordagens principais empregando tal noção.

A primeira, representada por autores norte-americanos que, segundo Barato (2001), privilegia o mercado de trabalho, tendo como foco o desempenho requerido pelas organizações. Steffen (1999) a classifica como comportamentalista. Já a segunda abordagem é representada por autores majoritariamente europeus. Para Barato (2001), a ênfase dessa corrente situa-se no vínculo entre trabalho e educação. Entre os europeus, Steffen (1999) faz, no entanto, distinção entre a perspectiva inglesa, de caráter funcionalista, centrada na definição de perfis organizacionais; e, a francesa, que evidencia a aprendizagem como fator chave para o desenvolvimento de competências profissionais, aos moldes do construtivismo.

Zarifian (2001), um dos principais representantes da escola francesa, destaca que a competência se manifesta e é avaliada quando mobilizada em uma situação profissional concreta, ou seja, na relação prática do indivíduo com o trabalho. Sob esse enfoque, a competência exerce-se com base em três premissas fundamentais: 1. Tomada de iniciativa e assunção de responsabilidades; 2. Entendimento dos aspectos práticos da situação em que é demandada, tendo por base os conhecimentos adquiridos; 3. Mobilização ou compartilhamento de experiências, a partir de redes e pessoas.

Outro representante da escola francesa, Le Boterf (2003) também associa a competência à experiência. Para ele, o indivíduo com a sua história de vida, educação formal e vivência profissional constitui o profissional competente, além dos atributos requeridos para a mobilização desses conhecimentos e capacidades em uma dada situação, permitindo-lhe atuar em contextos cada vez complexos, assumindo maiores graus de responsabilidade.

Para Le Boterf (2003), no entanto, a competência profissional comumente incorpora três elementos de referência: conhecimento (saberes), habilidades (saber-fazer) e atitudes (saber-ser). Dessa forma, o autor reconhece que o indivíduo envolvido no processo de conhecimento ou de compreensão é guiado por sistemas de valores e de significações, bem como por modelos socialmente compartilhados. Em decorrência, a competência não está dissociada das políticas e práticas organizacionais, ao que valorizam ou depreciam, aos circuitos de informação que geram e à concepção de papéis ou funções que instituem. Havendo, portanto, políticas e práticas organizacionais que podem favorecer a competência, enquanto outras a dificultam ou mesmo as destroem (KILIMNIK e SANT'ANNA, 2006). 
Mais recentemente, a noção de competência tem-se ampliado, visando incorporar novas questões como, por exemplo, a necessidade de maior articulação entre competências organizacionais, individuais e as estratégias organizacionais; maior integração entre competência e políticas e práticas de gestão; bem como no reconhecimento de que cabe às empresas importante papel de estimular e dar o suporte necessário para que as pessoas possam efetivamente dispor de ambiências organizacionais que lhes permitam desenvolver e aplicar sua competência (KILIMNIK e SANT'ANNA, 2006; RUAS et al., 2005; DUTRA, 2004; FLEURY e FLEURY, 2001).

\subsection{COMPETÊNCIAS DOCENTES}

A noção de competência ressurge em ímpeto, no campo educacional, notadamente a partir dos anos 1990, relacionada com a revalorização de discussões em torno da aprendizagem de adultos e a formação de professores para o ensino profissional vis-à-vis a formação para a cidadania, assumindo conteúdos e sentidos não necessariamente idênticos nessas diferentes áreas mas, contribuindo para o debate e a evidenciação de dissonâncias entre os investigadores de diferentes campos, professores e empresas.

De acordo com Paiva e Melo (2009), o processo de profissionalização dos professores caminha no sentido do reconhecimento social de suas competências para a formação de cidadãos e trabalhadores, cujos processos de desenvolvimento, por mais individualizados e individualizantes que se constituam, têm contribuído para sua diferenciação em relação a outros grupamentos profissionais, tanto no que se refere às suas especialidades e potenciais áreas de atuação, quanto a aspectos didático-pedagógicos.

Em pesquisa objetivando identificar, apresentar e analisar percepções de professores universitários acerca de suas competências docentes e profissionais, bem como de sua gestão no âmbito das instituições universitárias em que atuam, Paiva e Melo (2009) detectaram, todavia, a necessidade de condições - suporte organizacional - que favorecem o desenvolvimento e mobilização das competências docentes, em especial no que tange a seus componentes cognitivos, funcionais, comportamentais, éticos e políticos. Igualmente, enfatizam a relevância de ampliação do caráter interativo e multidimensional da profissão. Sobre dispositivos utilizados no processo de gestão da competência profissional docente ressaltam, também, aspectos de responsabilidade do próprio sujeito - tais como o 
autodesenvolvimento e a aprendizagem contínua - corroborando o caráter auto direcionado da carreira.

Paiva e Melo (2009) fazem menção, ainda, aos esforços pessoais e institucionais, assim como societais. Nesse sentido, apontam que as universidades não são dotadas de claras políticas de gestão de pessoas, bem como nem sempre o profissional docente a elas se submete, quer por ignorância, necessidade de manter-se com certo grau de descolamento da instituição, forma de vínculo trabalhista, ou mesmo devido a uma autonomia superestimada. Já sob o enfoque da sociedade, para Paiva e Melo (2009), a profissionalização de professores é frequentemente vista de forma positiva, sendo esses profissionais associados a contribuições efetivas às demais profissões.

Corroborando os autores acima, Saviani (1996) reforça a necessidade de o professor dominar saberes que se inter-relacionam, colocando em foco a educação como a determinante dos saberes e não o contrário. Segundo ele, os saberes, como aquisições técnicas isoladas, são inexpressivos. Dessa forma, o trabalho docente deve levar à produção de conhecimentos que considerem, ao mesmo tempo, um processo de dialética e subjetivação.

Nesse sentido, para Pimenta e Anastasiou (2010), o principal desafio vivenciado por esses profissionais está na ação de pesquisar o ensinar, seja, de inicio, na identificação da área de atuação como profissional docente, seja na revisão, com seus alunos, das atividades práticas em sala de aula. Segundo as autoras, as principais práticas do docente devem estar vinculadas ao tanto ao transmitir quanto ao mobilizar os conhecimentos trabalhados, situando o tempo, os resultados e os métodos de ensinar e aprender. O profissional docente deve, portanto, ter as competências necessárias para realizar e intensificar tal processo contínuo e sistêmico de pesquisa.

Em suma, percebe-se crescente nível de exigência em relação ao professor acadêmico. Se no passado bastavam os conhecimentos técnicos para a ocupação do cargo, atualmente, há exigência de maior especialização, atualização contínua, pesquisa e produção de conhecimento de forma multidimensional. Como resultado, evidencia e se justifica a razão do interesse científico no que se refere a quais atributos de competências esses professores precisam deter e que dispositivos utilizam-se para sua mobilização. 


\section{ASPECTOS METODOLÓGICOS}

Quanto à abordagem, esta pesquisa, seguindo prerrogativas de estudo anterior sobre o tema, conduzido por Kilimnik et al. (2011), pode ser caracterizada como de natureza qualitativa. Segundo Alves-Mazzotti e Gewandsznajder (1999), uma pesquisa qualitativa implica conceber o pesquisador como o principal instrumento de investigação. Partindo desse pressuposto, a escolha dessa abordagem fez-se pertinente, haja vista o objetivo de desenvolver a investigação numa ótica predominantemente compreensiva e interpretativa que exige do pesquisador uma postura crítica no que tange à percepção e à assimilação de indicadores que o auxiliam na clarificação das várias facetas do problema de pesquisa.

Quanto aos fins, ela pode ser caracterizada como de natureza descritiva, na medida em que se propõe expor características de um dado fenômeno. Isto, na medida em que as pesquisas descritivas expõem características de uma determinada população ou de determinado fenômeno. Pode também estabelecer correlações entre variáveis e definir sua natureza. Não tem compromisso de explicar os fenômenos que descreve, embora sirva de base para tal explicação.

Já quanto aos meios, optou-se pelo método de estudo de campo, o qual centra-se no estudo de um único grupo ou comunidade em termos de estrutura social, ressaltando a interação de seus componentes.

\subsection{COLETA DE DADOS}

Para a coleta de dados foi aplicada a técnica de entrevista semiestruturada e em profundidade, tendo como sujeitos de pesquisa, docentes de variadas formações e que atuam ou atuavam quando da realização do levantamento empírico de dados conduzido por Kilimnik et al. (2011) - em cursos de graduação e pós-graduação em administração na região metropolitana de Belo Horizonte (MG). Dos 50 respondentes da primeira pesquisa, os quais procederam, na ocasião, a transições de carreira do mundo corporativo para o acadêmico, foram localizados e entrevistados 25 indivíduos.

Cabe ressaltar que dentre os entrevistados há aqueles que, atualmente, estão ligados apenas à atividade docente e outros que conciliam o trabalho nas organizações e na academia e, ainda, os que não mais encontram-se na academia. 


\subsection{TRATAMENTO DOS DADOS}

Os dados obtidos via entrevistas foram transcritos, tabulados e, posteriormente, analisados à luz de pressupostos da análise de conteúdo, conforme propostos por Bardin (2006).

Segundo Bardin (2006), pode-se entender por análise de conteúdo um conjunto de técnicas de análise de comunicações que contêm informação sobre o comportamento humano, atestado por uma fonte documental. Na análise de conteúdo são utilizados procedimentos sistemáticos e objetivos para descrever o conteúdo das mensagens, assim como os indicadores quantitativos e não quantitativos, que possibilitam inferir os conhecimentos relativos às condições de produção e/ou recepção das variáveis inferidas dessas mensagens.

Para auxílio no processo de análise do conteúdo coletado foi utilizado o software de análise qualitativa de dados QDA Miner. De acordo com Moro e Sanchez-Criado (2005), o QDA Miner permite a realização de análises estatísticas, sem perder de vista as unidades de sentido do texto.

\section{APRESENTAÇ̃̃O E DISCUSSÃO DOS RESULTADOS}

Tendo em vista o objetivo geral da pesquisa - identificar competências associadas à docência em nível superior para profissionais que vivenciaram, no passado recente, transições de carreira do mundo corporativo para docência - foi possível identificar um conjunto de códigos que representam as competências relatadas pelos participantes.

Tais códigos foram, então, organizados em categorias, visando uma sequência lógica que permitisse uma compreensão mais sistemática de seus elementos. Os aspectos levantados, contudo, apresentam interfaces com outros códigos. Isto, na medida em que se referem a realidades sociais complexas. Dessa forma, as subdivisões dentro de cada categoria não são excludentes entre si, de maneira que os percentuais das tabelas podem exceder ao percentual cem por cento.

\subsection{PERFIL DOS RESPONDENTES}

Conforme previamente mencionado, a escolha dos profissionais pesquisados seguiu o critério de entrevistar os mesmos participantes de pesquisa anterior, conduzida por Kilimnik at al. (2011). As dificuldades de contato, assim como o longo tempo decorrido entre uma 
pesquisa e outra, fez com que o número de entrevistados finais fosse menor que o grupo original, de 50 participantes. Conforme dito anteriormente, o grupo estudado nesta pesquisa envolveu 25 indivíduos, exatamente $50 \%$ dos entrevistados da pesquisa anterior, o que, contudo, foi considerado satisfatório, dada a riqueza de informações obtidas, somadas àquelas da pesquisa anterior.

No que se refere à formação básica dos respondentes, a grande maioria advém de áreas de administração (41,38\%), psicologia (37,93\%) e comunicação social $(10,34 \%)$. Quanto à faixa etária, cerca de $40 \%$ distribui-se em faixas superiores a 40 anos. Há, porém, percentual representativo na faixa etária entre 36 a 40 anos (15,93\%), totalizando $65,93 \%$ com idade superior a 36 anos. Em relação ao estado civil é possível constatar que mais de $86 \%$ são casados, sendo 3,45\% divorciados. Finalmente, quanto à titulação, a grande maioria dos respondentes $(68,97 \%)$ detém o título de mestre em administração, seguida por $20,69 \%$ de doutores nessa mesma área.

Em linhas gerais, trata-se de um grupo qualificado e maduro, considerado adequado e capacitado a expressar suas percepções e vivências acerca da transição de carreira vivida e ao conjunto dos aspectos investigados.

\subsection{COMPETÊNCIAS DOCENTES}

Em relação às competências docentes, análise dos dados, procedida com o auxílio do QDA Miner, permitiu a identificação de oito categorias de competências: Conhecimento Especifico da Área, Relacionamento Interpessoal, Experiência de Mercado, Comunicação, Didática, Capacidade de Comprometimento, Inteligência Emocional e Liderança.

Como competência mais relevante à docência, unanimidade dos profissionais que vivenciaram transição de carreira do mundo corporativo para a academia investigados, salientou o Conhecimento especifico da Área de Atuação. Nessa dimensão, foram agrupadas 31 citações, incluindo as que seguem:

Então, eu preciso ter competências que me aproximem do aluno, que façam com que ele queira aprender. Ter conhecimento da área é uma competência que me permite fazer isso. (Entrevistada 21, 33 anos)

Você tem que ter uma base conceitual muito forte, conhecimento especifico da área, né? Até pra você repensar modelos que já estão pré-concebidos, saber, por exemplo, o que e já foi feito pra que você não cometa os mesmo erros, ou pelo menos, toma aquilo como referência. (Entrevistado 4, 41 anos) 
Eu acho que o importante é que o aluno reconheça no professor, essa capacidade, que tenha a legitimidade do conhecimento da área que ele ensina, conhecimento específico. O professor não pode ser um professor de... Que lê aba de livro, ou vai dar uma aula e lê um artigo e manda o aluno ler pra discutir e ser feliz, ele tem que ter conhecimento! (Entrevistada 10, 58 anos)

$\mathrm{Na}$ sequência, tem-se Relacionamento Interpessoal, indicada por $76,0 \%$ dos respondentes:

Eu percebo que, essa competência, da relação interpessoal na sala de aula, é importantíssima. Isso cria um compartilhamento com professor e aluno dentro da sala de aula, transforma o aluno como principal protagonista na sala de aula, então a relação interpessoal, eu acho que, ela é uma competência hoje, essencial, nesse mundo acadêmico, que nós vivemos. (Entrevistado 11, 56 anos)

Primeiramente, relacionamento interpessoal. Esse é fundamenta! Antes eu só achava que o conhecimento bastava. Mas agora, mais maduro, eu vejo que alinhado ao conhecimento nós precisamos ter um bom relacionamento interpessoal com os alunos. (Entrevistado 20, 50 anos)

Em seguida, registra-se a competência Experiência de Mercado (19 citações). A partir das análises, é possível constatar que a experiência é percebida como uma das principais vantagens competitivas entre os indivíduos que fizeram a transição do mundo corporativo para o acadêmico. Além de ter experiência é fundamental, no entanto, saber utilizá-la:

Da questão de competências necessária como professora, e é uma dos pontos fortes que eu tive, foi exatamente, o que eu levava pra sala de aula, num era uma visão acadêmica, de livros e etc, né? Eu levava uma visão prática também, então e eu conseguia juntar as duas coisas, né? Eu comecei a acrescentar à teoria a minha experiência do mundo corporativo pra dentro da sala de aula, a minha experiência, trazer exemplos práticos, questionamentos, discussões de vivências que eu tinha tido no mundo corporativo, então, eu acredito que esse talvez tenha sido o meu ponto mais alto, sabe? Ter essa competência de transformar a prática em aula. (Entrevistada 15, 47 anos)

Boa comunicação também se evidencia como competência-chave para $48,0 \%$ dos pesquisados:

Outra competência é comunicação. E comunicação em todos os níveis né? A capacidade de comunicação tem que ser fantástica, senão... Que professor é esse? Eu acho que uma das competências maiores, é a comunicação. Saber falar, se expressar... (Entrevistado 13, 41 anos)

Seguem-se as competências Didática (28,0\%), Capacidade de Comprometimento (16,0\%) e Inteligência Emocional (16,0\%):

Para um professor, que quer ter sucesso na carreira acadêmico, de professor, de pesquisador, a competência que ele tem que ter, é a capacidade de sintetizar, de ter boa didática, conseguir colocar os conhecimentos no papel, buscar o conhecimento, sintetizar aquilo de forma cientifica né, e replicar da melhor forma possível, utilizando a melhor didática. Organizar aquilo de forma científica e produzir conhecimento, pra que outras pessoas estudem. (Entrevistado 19, 46 anos) 
Por fim, a competência que obteve menor escore foi Liderança, referida por somente $12,0 \%$ dos entrevistados (3 citações). Acredita-se que, devido a mudanças de perspectiva do papel do professor - do professor como autoridade para o facilitador da aprendizagem - tal competência tenha sido, de algum modo, ressignificada:

O professor ele tem que liderar, quando a gente fala que o professor ele tem que, por exemplo, motivar os alunos. Motivar os alunos seria você trabalhar para você vender uma perspectiva pra eles, e fazer com que eles se engajem naquilo. Então eu acho que uma competência é a liderança dentro de sala de aula. Onde você. Hoje não existe mais autoridade dentro de sala de aula, entendeu? Não há professor que sobrevive encima de autoridade, ele tem que ser um líder. (Entrevistado 5, 34 anos)

A Tabela 1, apresenta uma síntese das competências, incluindo o número de citações e a descrição associada a cada uma, conforme dados dos entrevistados.

Tabela 1 Competências docentes

\begin{tabular}{|c|c|c|c|}
\hline Competências Docentes & Descrição & Citações & $\begin{array}{c}\text { Entrevistas } \\
(\mathrm{N} \mathrm{e} \%)\end{array}$ \\
\hline Conhecimento Específico da Área & $\begin{array}{l}\text { Ter conhecimento específico da área } \\
\text { de formação }\end{array}$ & 31 & $\begin{array}{c}25 \\
100,00 \%\end{array}$ \\
\hline Relacionamento Interpessoal & Ter uma boa relação interpessoal & 24 & $\begin{array}{c}19 \\
76,00 \% \\
\end{array}$ \\
\hline Experiência de Mercado & $\begin{array}{l}\text { Ter experiência do mundo corporativo } \\
\text { e saber transmitir tal experiência }\end{array}$ & 47 & $\begin{array}{c}19 \\
76,00 \% \\
\end{array}$ \\
\hline Comunicação & $\begin{array}{l}\text { Ter boa comunicação e aptidão oral } \\
\text { para transmitir o conteúdo }\end{array}$ & 12 & $\begin{array}{c}12 \\
48,00 \% \\
\end{array}$ \\
\hline Didática & Ter didática & 7 & $\begin{array}{c}7 \\
28,00 \% \\
\end{array}$ \\
\hline Capacidade de Comprometimento & $\begin{array}{l}\text { Ser comprometido com o mundo } \\
\text { acadêmico e com as atividades } \\
\text { docentes }\end{array}$ & 4 & $\begin{array}{c}4 \\
16,00 \% \\
\end{array}$ \\
\hline Inteligência Emocional & $\begin{array}{l}\text { Ter inteligência emocional para saber } \\
\text { lidar com as dificuldades da docência }\end{array}$ & 6 & $\begin{array}{c}4 \\
16,00 \%\end{array}$ \\
\hline Liderança & Ser um líder dentro de sala de aula & 3 & $\begin{array}{c}3 \\
12,00 \%\end{array}$ \\
\hline
\end{tabular}

Fonte: Dados da pesquisa - QDA Miner.

Nota: As categorias não são excludentes entre si, de maneira que os percentuais podem exceder $100 \%$.

Avançando para uma análise comparativa com dados Kilmnik et al. (2011), cabe destacar recorrência significativa das competências docentes entre os dois momentos das pesquisas. A Figura 1, relaciona as categorias de competências identificadas em ambos os estudos - 2011 e 2015, respectivamente - apresentando equivalências entre os códigos identificados. 


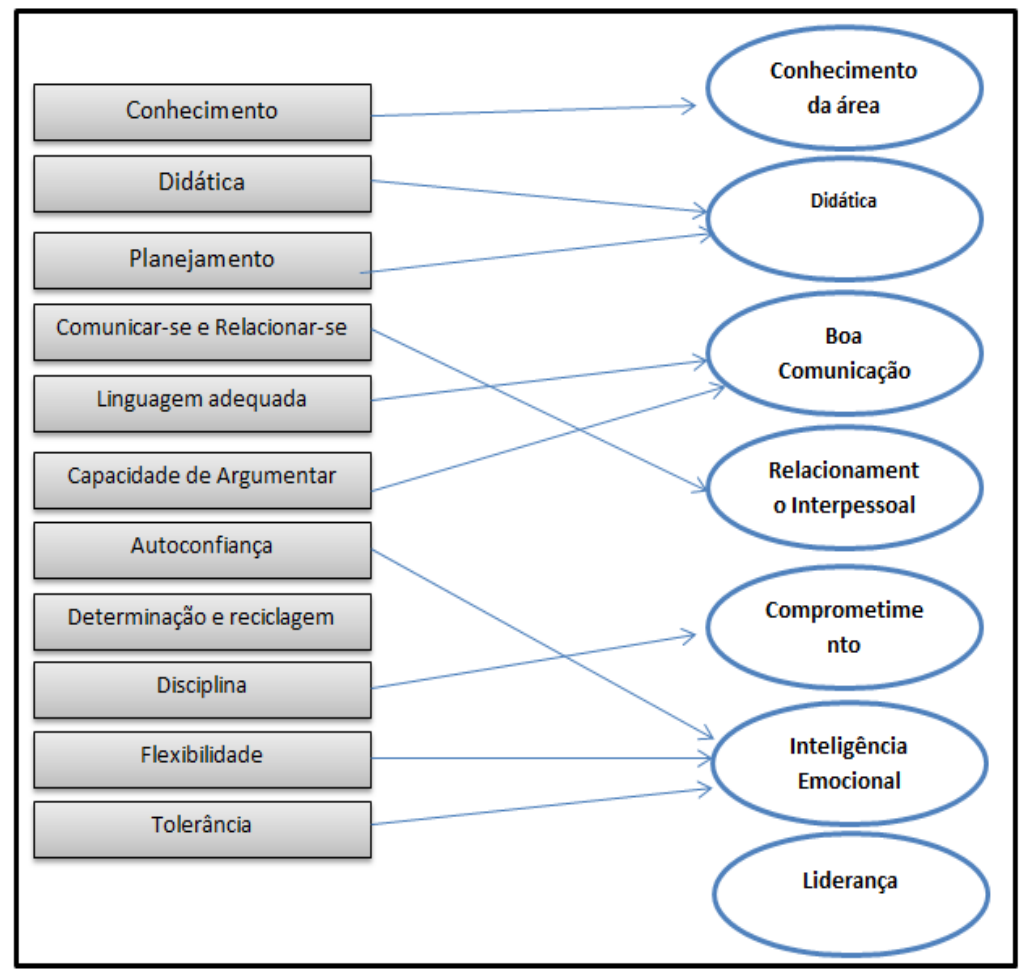

Figura 1 Competências identificadas nas duas pesquisas analisadas Fonte: dados da pesquisa

Pelos dados da Figura 1, constata-se que somente a competência Determinação $e$ Reciclagem, identificada na pesquisa anterior, não foi explicitamente identificada na atual. Tem-se, também, que a competência Liderança foi evidenciada somente na pesquisa atual, muito embora, por número reduzido de respondentes.

\subsection{ESTRATÉGIAS DIDÁTICO-PEDAGÓGICAS}

A partir do conjunto dos dados coletados foi possível também identificar principais estratégias de ensino-aprendizagem adotadas pelos pesquisados. Como resultado é perceptível a prevalência de estratégicas didático-pedagógicas tradicionais - aulas expositivas $(56,0 \%)$ e estudos de caso (44,0\%). O diferencial dos egressos do mundo corporativo, segundo eles, reside, no entanto, no relacionamento entre os conhecimentos repassados e os processos por eles experienciados no cotidiano das organizações:

Utilizo muito as aulas expositivas. Mas sempre relacionando experiências, seja minha ou deles, para o entendimento da matéria daquele dia. (Entrevistado 20, 50 anos)

É, eu utilizo aula expositiva, como o apoio de PowerPoint e Data show. Eu gostava muito dessa aula, a gente ia construindo junto o conhecimento, e à medida que esse 
conhecimento ia sendo construído, a gente ia fazendo apontamentos no quadro, eu acho que eles gostavam. (Entrevistada 24, 39 anos)

A técnica que eu mais utilizo e gosto é o estudo de caso. Como ele tinha um grande suporte para construir o raciocínio. (Entrevistado 14, 55 anos).

Outra estratégia didático-pedagógica que denota atenção refere-se à adoção de dinâmicas em sala de aula (40,0\%). Tal estratégia é também frequentemente associada a experiências no mundo corporativo, conforme evidenciam diversos relatos:

Isso é uma grande demanda dos alunos, hoje, né? E eles não querem saber da gente ficar só dando aula teórica, né? Querem saber das coisas na prática. Então, eu utilizo de técnicas que considero inovadora como a dinâmica para tentar exemplificar o que acontece nas empresas. (Entrevistado 12, 33 anos)

Eu utilizo, eu sempre começo o semestre, quebrando o gelo com meus alunos, eu faço dinâmicas com eles em grupo, onde os alunos, eles podem trazer a sua percepção e ver a do colega e também das organizações. É uma atividade que eu faço com eles, usando alguns recursos mais lúdicos. (Entrevistado 4, 41 anos)

Todas as minhas aulas eram práticas. Então, tudo que eu fazia de teoria, eu dava uma dinâmica, para poder fazer com que aquele aluno entendesse. Dessa forma, então, foi a partir de dinâmicas que eu pude exemplificar. (Entrevistada 3, 41 anos)

A utilização de filmes também se encontra presente nos depoimentos de $36,0 \%$ dos pesquisados:

Procurei trazer muitos vídeos, procurei usar recursos visuais através dos vídeos, né? O visual, que hoje é necessário, você precisa segurar a turma. Né? É uma linguagem fácil, desde o começo usei vídeo demais. (Entrevistada 15, 47 anos)

Por exemplo, a disciplina política e poder, eu trabalhava com alguns filmes, mas eu não usava minha aula, eu usava um horário de casa dos alunos? Se eu ficasse passando só filme em sala de aula eu estaria, entre aspas, enrolando meus alunos com duas horas a menos de aula, então eu tinha técnicas muito variadas né? Até para o cinema eu já os levei para assistir filmes. (Entrevistada 10, 58 anos)

Na sequência, têm-se seminários (28,0\%), leitura de textos, livros e artigos $(20,0 \%)$, dramatizações $(16,0 \%)$ e visitas técnicas, adotadas por apenas $4,0 \%$ dos respondentes:

Eu gosto muito de trabalhar com esquema de leitura, de discussão de artigos e seminários, eu trabalho muito com isso, eu trabalho com seminário, e leitura. (Entrevistada 17, 33 anos)

O teatro foi quando eu dava aula na pós-graduação, para engenheiros de segurança do trabalho, eu dava aula de conhecimento didático e pedagógico, porque esses engenheiros seriam pessoas responsáveis por educar e conscientizar os colegas deles de trabalho, com relação de segurança. Eu queria mostrar para eles as quatro visões pedagógicas principais, para que eles comparassem com o profissional. Então era, cada grupo, tinham que fazer um pequeno teatro que representasse pra gente aquela linha pedagógica. (Entrevistada 24, 39 anos) 
Também eu utilizo muito a questão das visitas técnicas, né? Então, tem algumas empresas já cadastradas, e que a gente consegue visitar e... fazer, essa peça de utilidade técnica, né? Depois dá para você pegar o que foi visto e trabalhar teoricamente, sabe? (Entrevistada 17, 33 anos)

A Tabela 2 sintetiza os dados coletados e analisados a partir do QDA Miner.

Tabela 2 Estratégias didático-pedagógicas

\begin{tabular}{llcc}
\hline $\begin{array}{c}\text { Estratégias Didático- } \\
\text { Pedagógicas }\end{array}$ & \multicolumn{1}{c}{ Descrição } & Citações & $\begin{array}{c}\text { Entrevistas } \\
\text { (N e \%) }\end{array}$ \\
\hline Aulas expositivas & $\begin{array}{l}\text { Demonstração do conteúdo das aulas de forma } \\
\text { expositiva }\end{array}$ & $\begin{array}{c}14 \\
56,00 \%\end{array}$ \\
\hline Estudo de caso & $\begin{array}{l}\text { Utilização de exemplos e situações problemáticas para } \\
\text { elaboração de exercícios }\end{array}$ & 12 & $\begin{array}{c}11 \\
44,00 \%\end{array}$ \\
\hline Dinâmicas & Desenvolvimento de atividade de forma prática & 10 \\
\hline Filmes & Utilização de filmes nas aulas & 11 & $40,00 \%$ \\
\hline Seminários & Seminários apresentados em sala de aula & 9 \\
\hline Leituras de textos, livros & Leitura de materiais de apoio & $96,00 \%$ \\
\hline artigos. & Apresentações de esquetes em sala de aula para ilustrar & 7 \\
\hline temas e assuntos relacionados & 5 & $28,00 \%$ \\
\hline Visita Técnica & Visitas em empresas para demonstrações de pratica & 1 & 5 \\
\hline \hline
\end{tabular}

Fonte: Dados da pesquisa - QDA Miner.

Nota: As categorias não são excludentes entre si, de maneira que os percentuais podem exceder $100 \%$.

Isso posto, discorre-se, no item a seguir, a considerações finais sobre o estudo, seus achados e resultados.

\section{CONSIDERAÇÕES FINAIS}

De forma geral, o que se pode inferir é que as competências apresentadas na pesquisa anteriormente conduzida por Kilimnik et al. (2011) - assim como em estudos prévios conduzidos sobre o tema por Kilimnik, Correa e Oliveira (2009a) e Kilimnik e Correa (2009b) - foram corroboradas pelas competências identificadas na pesquisa atual, seja de forma direta, seja por meio de equivalências. Os pesquisados mantiveram suas opiniões em relação às competências necessárias para o desempenho na carreira acadêmica, mesmo passados cinco anos da primeira investigação. 
Vale ressaltar, no entanto, que, na presente pesquisa, ficou mais evidente que a experiência profissional, apesar de ser um dos pontos fortes no imaginário de competência do docente oriundo do mundo corporativo, não se constitui suficiente, caso não seja associada com a teoria, gerando aprendizado.

O presente estudo indica, ainda, como estratégia didático-pedagógica mais recorrente, a tradicional aula expositiva, acompanhada do estudo de caso e de dinâmicas em grupo. Segundo os respondentes, a utilização dessas duas últimas técnicas associa-se às suas vivências no meio empresarial. Por meio delas, acreditam acessar mais facilmente a teoria. A aposta consiste no movimento da prática para a teoria e não o contrário. Elemento esse apontado como distintivo de sua atuação, comparativamente aos acadêmicos sem vivência junto ao contexto empresarial.

\section{REFERÊNCIAS}

ALVES-MAZZOTTI, A. J. GEWANDSZNAJDER, F. O método das ciências naturais e sociais: pesquisa quantitativa e qualitativa. São Paulo: Thomson, 1999.

BARATO, J. N. Competências essenciais e avaliação do ensino universitário. Brasília: UNB, 2001.

BARUCH, Y., Transformações nas carreiras: de trajetórias lineares para multidirecionais. In: KILIMINIK, Z. M. (Org.). Transformações e transições nas carreiras - Estudos nacionais e internacionais sobre o tema. São Paulo:Qualimark, 2011. Cap. 4, p. 85-98.

BARDIN, L. Análise de conteúdo. Lisboa: Edições Setenta, 2006.

DUBERLEY, J., Avaliando transições profissionais: da carreira científica para o empreendedorismo por meio de incubadoras de empresas In: KILIMINIK, Z. M. (Org.). Transformações e transições nas carreiras - Estudos nacionais e internacionais sobre o tema. São Paulo: Qualimark, 2011. Cap. 4, p. 57-84.

DUTRA, J. S. Gestão de pessoas por competências: modismo ou conceito em construção. In: DUTRA, J. Competências: conceitos e instrumentos para a gestão de pessoas na empresa moderna. São Paulo: Atlas, 2004

FLEURY, A.; FLEURY, M.T.L. Estratégias empresariais e formação de competências: um quebra-cabeças caleidoscópio da indústria brasileira. 2. ed. São Paulo: Atlas, 2001.

FLICK, U. Introdução à pesquisa qualitativa. 3. ed. Porto Alegre: Artmed, 2009.

GUNZ, H.; PEIPERL, M. (Ed.). Handbook of career studies. Thousand Oaks: Sage, 2007. 
KILIMNIK, Z. M.; RODRIGUES, S. B. Trajetórias e transição de carreiras: um estudo comparativo e longitudinal com profissionais de recursos humanos. In: KILIMNIK, Z. M. Transformações e transições nas carreiras: estudos nacionais e internacionais sobre o tema. Rio de Janeiro: Qualitymark, 2011, p. 253-78

KILIMNIK, Z. M.; CORREA, M. L. R.; OLIVEIRA, L. C. V. de. Da gerência para a docência: uma transição de carreira cada vez mais frequente na área de Administração In: II ENCONTRO GESTÃO DE PESSOAS E RELAÇÕES DE TRABALHO, 2009, Curitiba. Anais... Curitiba: EnGPR, 2009a.

KILIMNIK, Z. M. ; CORREA, M. L. R. ; O., L. C. V. Da gerência para a docência: uma difícil transição de carreira?. In: 6 INTERNATIONAL CONFERENCE OF THE IBEROAMERICAN ACADEMY OF MANAGEMENT, 2009, Buenos Aires. Anais.... Buenos Aires: Iberoamerican Academy of Management, $2009 \mathrm{~b}$.

LE BOTERF, G. Desenvolvendo a competência dos profissionais. Porto Alegre: Artmed, 2003.

MORO, M., SANCHEZ-CRIADO, T. Taller de metodología de investigación - parte II. Herramientas básicas para la investigación cualitativa: introducción al manejo del programa de análisis cualitativo QDA Miner 1.2.. Madrid: UAM. 2005. Manuscrito en desarrollo.

PAIVA, K. C. M.; MELO, M. C. O. L. Competências profissionais docentes e sua gestão em universidades mineiras. In: HELAL, Diogo Henrique. (Org.) Gestão de pessoas e competências: teoria e pesquisa. Curitiba: Juruá, 2009.

PIMENTA, S. G.; Anastasiou, L. G. C. Docência no ensino superior. São Paulo: Cortez, 2010.

RIVERIN-SIMARD, D. Transitions profissionelles: choix et stratégies. Québec: Le Press de L’université de Laval, 1993.

RUAS, R. Mestrado modalidade profissional: em busca da identidade. RAE, São Paulo, v. 43, n. 2, 2003.

SIMENDINGER, E. et. al A transição de carreira da gerência para a docência. In:

KILIMINIK, Z. M. (Org.). Transformações e transições nas carreiras - Estudos nacionais e internacionais sobre o tema. São Paulo: Qualimark, 2011. Cap. 4, p. 85-98.

STEFFEN, I. Modelos e competências profissionais. [S.1]:[S.n], 1999. Mimeografado.

SAVIANI, D. Os saberes implicados na formação do professor. São Paulo: UNESP, 1996.

VELOSO, E.F.R. Carreiras sem fronteiras e transição profissional no Brasil: desafios e oportunidades para pessoas e organizações. São Paulo: Atlas, 2012.

YIN, R. K. Estudo de caso: Planejamento e métodos. Porto Alegre: Bookman, $2^{\mathrm{a}}$ edição, 2001.

ZARIFIAN, P. Objetivo competência: por uma nova lógica: São Paulo: Atlas, 2001. 